\title{
Do documentário histórico ao imaginário antropológico do regime militar brasileiro: uma leitura simbólica sobre o golpe de 1964
}

\section{Eduardo Portanova Barros}

Pós-Doutor; Universidade do Vale do Rio dos Sinos, São Leopoldo, RS, Brasil eduardoportanova@hotmail.com

\section{Danilo Fantinel}

Doutorando; Universidade Federal do Rio Grande do Sul, Porto Alegre, RS, Brasil danilo.fantinel@gmail.com

\section{Resumo}

Este artigo oferece uma leitura simbólica sobre o imaginário que movimenta seis filmes documentários relativos ao regime militar brasileiro. Elegemos os Estudos do Imaginário como heurística apropriada à revelação de imagens simbólicas, simbolismos e narrativas míticas estimuladas pelas representações fílmicas tanto do governo de João Goulart quanto do golpe civil-militar que o tirou da Presidência da República. A partir de documentação audiovisual, acessamos os elementos constitutivos do imaginário que move as obras. Assim, esperamos proporcionar uma complementação ao entendimento sobre esse período obscuro da sociedade brasileira, bem como oferecer uma abordagem alternativa à pesquisa em Comunicação sobre documentários históricos.

\section{Palavras-chave}

Comunicação. Regime militar. Ditadura brasileira. História do Brasil. Imaginário. Documentário.

\section{0 imaginário da ditadura brasileira movido por documentários}

O ano de 2014 marcou as cinco décadas da instauração do regime militar no Brasil, cujo golpe de $1^{\text {o }}$ de abril de 1964 deu início a uma ditadura que perdurou até 1985.0 
momento histórico, que sempre ecoou no cinema e na pesquisa acadêmica nacionais, ganhou ainda mais atenção em seu cinquentenário. Neste trabalho, resultado de uma dissertação de mestrado ${ }^{1}$, propomos um retorno ao tema na tentativa de oferecer uma leitura simbólica sobre o imaginário que movimenta seis filmes documentários relativos à ditadura. Para tanto, elegemos os Estudos do Imaginário como heurística apropriada à revelação de imagens, simbolismos e narrativas míticas presentes no período entre o governo de João Goulart e o golpe civil-militar que o tirou da Presidência da República.

Transdisciplinar, a perspectiva fundada pela Escola de Grenoble reflete sobre a imaginação simbólica do homem, capaz de dinamizar um imaginário antropológico cujos conteúdos são expressos em obras culturais, como documentários. Nosso material de leitura é a documentação textual, sonora e visual articulada em narrativa fílmica, que permite acessar os elementos constitutivos do imaginário que move os longas-metragens.

Juntos, os filmes selecionados apresentam temáticas complementares. Jango (1984), de Silvio Tendler, remonta a trajetória política de João Goulart, o 24o presidente do Brasil. Cidadão Boilesen (2009), de Chaim Litewski, retrata a vida de Henning Albert Boilesen, empresário dinamarquês radicado no Brasil apontado por presos políticos e pesquisadores como colaborador da repressão e defensor da tortura. Marighella (2011), de Isa Grispum Ferraz, resgata os percursos do militante da luta armada Carlos Marighella. $O$ dia que durou 21 anos (2012), de Camilo Tavares, apresenta provas da influência dos governos de John Kennedy (1961-1963) e de Lyndon Johnson (1963-1969) no golpe e na ditadura. Dossiê Jango (2013), de Paulo Henrique Fontenelle, recupera a figura do ex-presidente com destaque à Operação Condor, coordenada entre os regimes militares de Brasil, Argentina, Uruguai e Chile para exterminar dissidentes políticos no Cone Sul. Já em Militares da democracia: os militares que disseram não (2014), Silvio Tendler apresenta histórias dos homens de farda que se negaram a apoiar o golpe e a repressão político-social organizada pelas Forças Armadas.

Os filmes escolhidos apresentam importantes enunciados sobre a ditadura com base em documentação. Por outro lado, despertam inquietações relativas aos conteúdos simbólicos movimentados justamente por sua carga documental. Essa dualidade reforça o debate a respeito da potência representativa deste formato fílmico. A própria conceituação do termo documentário é ainda hoje complexa, girando em torno de critérios sobre verdade,

\footnotetext{
1 A dissertação $O$ ovo da serpente, o mito do golpe de Estado positivo e a queda: do documentário histórico ao imaginário antropológico da ditadura militar brasileira foi defendida em dezembro de 2015 (FANTINEL, 2015).
} 
realidade e questões vinculadas ao regime da representação. Ainda assim, concordamos com Ramos (2013), para quem os documentários são narrativas destinadas a representações do real e asserções sobre o mundo, podendo ter enfoques histórico e político ${ }^{2}$.

Sendo resultado de um processo de retroalimentação constante, o imaginário se nutre tanto de elementos simbólicos ${ }^{3}$ quanto de imagens técnicas (FLUSSER, 2011), ao mesmo tempo em que alimenta e é alimentado por objetos culturais. Ou seja, o imaginário interage com a produção cultural originando-a, abastecendo-a e também resultando dela em um movimento contínuo, recíproco e incessante.

Portanto, os conteúdos simbólicos ecoados pela carga documental vêm justamente a constituir o imaginário da ditadura militar que movimenta os seis filmes estudados. Por sua vez, esse imaginário específico relativo aos documentários liga-se ao grande imaginário antropológico. Sua revelação poderá dar sentido simbólico e mítico a uma realidade representada pelos audiovisuais, que diz respeito à cultura e à história recente do Brasil.

Com isso, esperamos proporcionar uma complementação ao entendimento sobre um dos períodos mais obscuros da sociedade brasileira, bem como oferecer uma abordagem alternativa a documentários históricos estudados na pesquisa em Comunicação.

\section{Imaginário, mitocrítica, arquétipo e mito}

Entendido como um complexo sistema de imagens simbólicas ${ }^{4}$ resultantes do que Durand (2012) definiu como trajeto antropológico5, ou seja, a exata confluência entre as condutas inerentes à condição humana, pulsionais, e as coerções oriundas do contexto histórico-social, o imaginário configura-se como um campo simbólico transpessoal e transcultural fundante do homem, da sociedade e da história.

\footnotetext{
2 Como é o caso dos 53 títulos relativos ao regime militar brasileiro lançados entre 1964 e 2014, segundo o levantamento Filmografia Sobre o Regime Militar, realizado pelo grupo de pesquisa História e Audiovisual: circularidades e formas de comunicação (201-).

3 Entre esses conteúdos, as imagens simbólicas (DURAND, 2000), constitutivas do imaginário humano, se diferenciam das imagens técnicas (FLUSSER, 2011) sob vários aspectos. Produzidas pela imaginação criadora do homem (BACHELARD, 1990), essas imagens são imateriais, são vivenciadas pelo sujeito, estando mais próximas de sensações, sentimentos e emoções do que da racionalidade humana ou da própria visualidade que caracteriza as imagens técnicas. Imagens simbólicas não exigem decodificação estrita, sendo próprias a uma leitura multifocal que dê atenção a suas polissemia e aderência.

4 Imagens simbólicas convergem por homologia para formar simbolismos e constelações estruturantes do imaginário antropológico estudado por Durand (2012). Devido a sua polissemia, oriunda da convergência entre o que está dentro e o que está fora do sujeito, as imagens simbólicas guardam sentidos diversos que são apreendidos em maior ou menor grau conforme a experiência de cada indivíduo.

5 Também conhecido como trajeto do sentido.
} 
Ao enraizar o indivíduo culturalmente, o imaginário estimula sentidos por meio de imagens arquetípicas, simbolismos, narrativas míticas e metáforas. Assim, estabelece correspondência com estruturas simbólicas antepassadas. Visto que o homem contemporâneo repete mitos antigos em seu comportamento, há continuidade da mitologia ancestral na cultura atual.

A investigação dos elementos imaginários se dá pela mitocrítica, procedimento metodológico elaborado por Durand $(1996,1998$, 2012) pelo qual é feita a leitura simbólica dos conteúdos que emanam da produção cultural. Assim, torna-se importante propor esboços conceituais sobre imagens arquetípicas e mitos.

Para Durand, a pregnância da imagem e a recorrência do mito são elementos de um "paradigma antropológico específico" (1996, p. 146) diretamente ligado à "solução heurística do arquétipo" (1996, p. 150), pela qual este conteúdo do inconsciente coletivo (JUNG, 1978 , 2002) se coloca como raiz de todas as imagens. Seguindo Carl Gustav Jung, observamos os arquétipos como imagens ou potencialidades primordiais compartilhadas por seres humanos há gerações.

De forma ampla, mitos poderiam ser entendidos como antigas e recorrentes narrativas explicadoras da condição humana, capazes de articular imagens arquetípicas e propor sentidos que variam conforme os contextos históricos em que se manifestam. Conclui Durand (2012, p. 62) que, não sendo apenas o "reverso representativo de um ato ritual", o mito se apresenta mesmo como um sistema dinâmico de arquétipos, símbolos e esquemas ${ }^{6}$ que "tende a compor-se em narrativa".

O mito é já um esboço de racionalização, dado que utiliza o fio do discurso, no qual os símbolos se resolvem em palavras e os arquétipos em ideias. 0 mito explicita um esquema ou um grupo de esquemas [...], promove a doutrina religiosa, o sistema filosófico ou, como bem viu Bréhier, a narrativa histórica e lendária (DURAND, 2012, p. 63).

De fato, para Durand o mito é uma linguagem, uma narrativa simbólica, um conjunto discursivo de símbolos, no qual, porém, o símbolo é mais importante que os processos narrativos. Conforme o autor, “[...] a consciência mítica dá a primazia à intuição semântica, à

\footnotetext{
6 Durand recorre a Sartre, Burloud e Revault d'Allonnes, estes inspirados em Kant, para definir esquema (schème) como uma generalização dinâmica e afetiva de imagem, que constitui a factividade e a não-substantividade geral do imaginário. Conforme o antropólogo, o esquema aparenta-se ao que Piaget chama de "símbolo funcional" e ao que Bachelard chama de "símbolo motor". Porém, para Durand, o esquema não liga imagem e conceito, como em Kant, mas sim promove uma junção entre os gestos inconscientes da sensório-motricidade, as dominantes reflexas e as representações. "São estes esquemas que formam o esqueleto dinâmico, o esboço funcional da imaginação." (DURAND, 2012, p. 60).
} 
materialidade do símbolo, e visa à compreensão fideísta do mundo das coisas e dos homens." (DURAND, 1996, p. 42). Assim, explica que a matéria-prima do mito é existencial:

É a situação do indivíduo e do seu grupo no mundo que o mito tende a reforçar, ou seja, a legitimar. 0 mito é, simultaneamente, modo de conhecimento e modo de conservação. É, aliás, esta última característica que distingue o conhecimento mítico do conhecimento científico que é, no seu caso, técnica de transformação. É nas situações cosmológicas, escatológicas, teológicas, etc., que o mito vai encontrar o seu ponto de aplicação preferido (DURAND, 1996, p. 44).

No pensamento sobre as relações entre história e imaginário, Durand (2012, p. 390) entende as grandes imagens e narrativas como estruturantes e orientadoras do processo histórico: “[...] é o mito que vivifica com a sua corrente a imaginação histórica (historienne) e estrutura as próprias concepções da história." 0 autor identifica o mito como referencial necessário à compreensão histórica.

O mito vai ao encontro da história, atesta-a e legitima-a, tal como o Antigo Testamento e as suas "figuras" garantem a autenticidade histórica do Messias para um cristão. Sem as estruturas míticas, a inteligência histórica não é possível. Sem a expectativa messiânica - que é mítica - não há Jesus Cristo, sem o mito, a batalha de Philipes ou a de Waterloo não passariam de faits divers (DURAND, 1996, p. 87).

Ainda assim, Durand (1996) explica que o símbolo não se refere à história em si, ou ao momento cronológico de algum fato, mas sim àquilo que advém de suas significações. $\mathrm{Ou}$ seja, símbolo e mito estimulam a produção de sentido da perspectiva histórica. Dessa forma, o autor compartilha do pensamento de Eliade (2002), para quem a evolução do entendimento sobre o símbolo faz parte da reação contra o racionalismo, o positivismo e o cientificismo do século XIX durante a primeira metade do século XX.

Segundo Eliade (2002), o estudo do símbolo permite-nos conhecer melhor o homem que ainda não se compôs com as condições da história, pois cada ser histórico transporta consigo uma grande parte da humanidade anterior a ela. Esta parte a-histórica do ser humano traz uma memória de existência rica e completa. 0 autor não contesta a importância da história em si, mas explica que não é situando um símbolo em um único ponto de sua própria história que se resolverá o problema de se entender o que revela não uma versão particular de um símbolo, mas a totalidade de um simbolismo. Eliade (2002) ressalta que a história não consegue modificar radicalmente a estrutura de um simbolismo imanente, apesar de acrescentar continuamente novos sentidos a ele sem destruir sua estrutura original. Para o autor, mitos se degradam e símbolos se secularizam, mas nunca 
desapareceram, nem na mais positivista das civilizações, a do século XIX, nem durante as maiores crises da humanidade, como as grandes guerras.

Portanto, existe no mito articulador de imagens um núcleo de sentido que reconstitui narrativas ancestrais, cíclicas, estruturantes do homem, que elaboram problemáticas da existência, da simbolização e da significação durante sua partilha recorrente. Seu código interno não se modifica conforme contextos históricos, mas propõe sentidos que variam de acordo com os momentos em que o mito se manifesta. Assim, há uma significação do mundo e do ser atrelada ao mito, que assume novos sentidos conforme o momento histórico-social.

Nesta leitura simbólica, o imaginário sobre a ditadura brasileira se revela aos poucos. Passo a passo, a mitocrítica evidencia imagens, simbolismos e mitos ligados ao processo histórico. Os subtítulos abaixo pretendem organizar este conteúdo simbólico, colocando-o em perspectiva e propondo relações entre seus elementos.

\section{0 imaginário pré-golpe}

Em 1955, João Goulart foi eleito vice-presidente do Brasil na coligação PTB/PSD, obtendo mais votos que o presidente eleito, Juscelino Kubitschek. Naquela época, as votações para presidente e vice eram separadas. Em 1960, João Goulart foi reeleito vicepresidente no pleito que levou Jânio Quadros à presidência. Jânio, no entanto, liderou um governo apático, incapaz de completar os primeiros sete meses. Sua renúncia à Presidência se deu quando Jango estava em viagem oficial à China, em agosto de 1961.

Descontente com os posicionamentos de esquerda do vice-presidente, a elite militar nacional articula o bloqueio do retorno de Jango ao Brasil para impedir sua posse. Somente com o apoio da Campanha da Legalidade, liderada pelo então governador do Rio Grande do Sul, Leonel Brizola, Jango consegue voltar ao país. Assume como presidente em Regime Parlamentarista no dia 7 de setembro de 1961.

\subsection{0 simbolismo da terra}

Nacionalista, Jango cancela contratos de multinacionais e anuncia as Reformas de Base $^{7}$. Para ilustrar o programa político-administrativo, os filmes que são objeto de análise neste trabalho exibem imagens técnicas de agricultores e do movimento agrário. Essa carga

\footnotetext{
7 Planos de reestruturação econômica e social do Brasil
} 
imagética desperta a imaginação material teorizada por Bachelard (2001) tendo em vista os elementos da cosmologia grega ${ }^{8}$, especialmente no que diz respeito aos simbolismos e imagens poéticas ligadas à terra e aos devaneios da vontade que regem este elemento.

Conforme Bachelard (2001), a imaginação resulta da ação do homem sobre a matéria que compõe o mundo. Com documentação sobre agricultores trabalhando a terra, os documentários emitem simbolismos do dinamismo agrário, imagens simbólicas de ação e energia sobre o elemento duro, além do "vegetalismo terrestre" (BACHELARD, 2001, p. 53). Vertidos para o mundo histórico, esse conteúdo imaginário traduz a pujança produtiva dos pequenos trabalhadores rurais 9 .

As imagens técnicas documentarizantes sobre a reforma agrária articulam imagens simbólicas de autodeterminação ao ecoar não apenas devaneios de vontade sobre a terra, que objetivam a dominação da matéria (BACHELARD, 2001), como também os desejos sociais de distribuição adequada das riquezas do solo.

Figura 1 - João Goulart em projetos agrícolas e em comícios sobre as reformas de base.

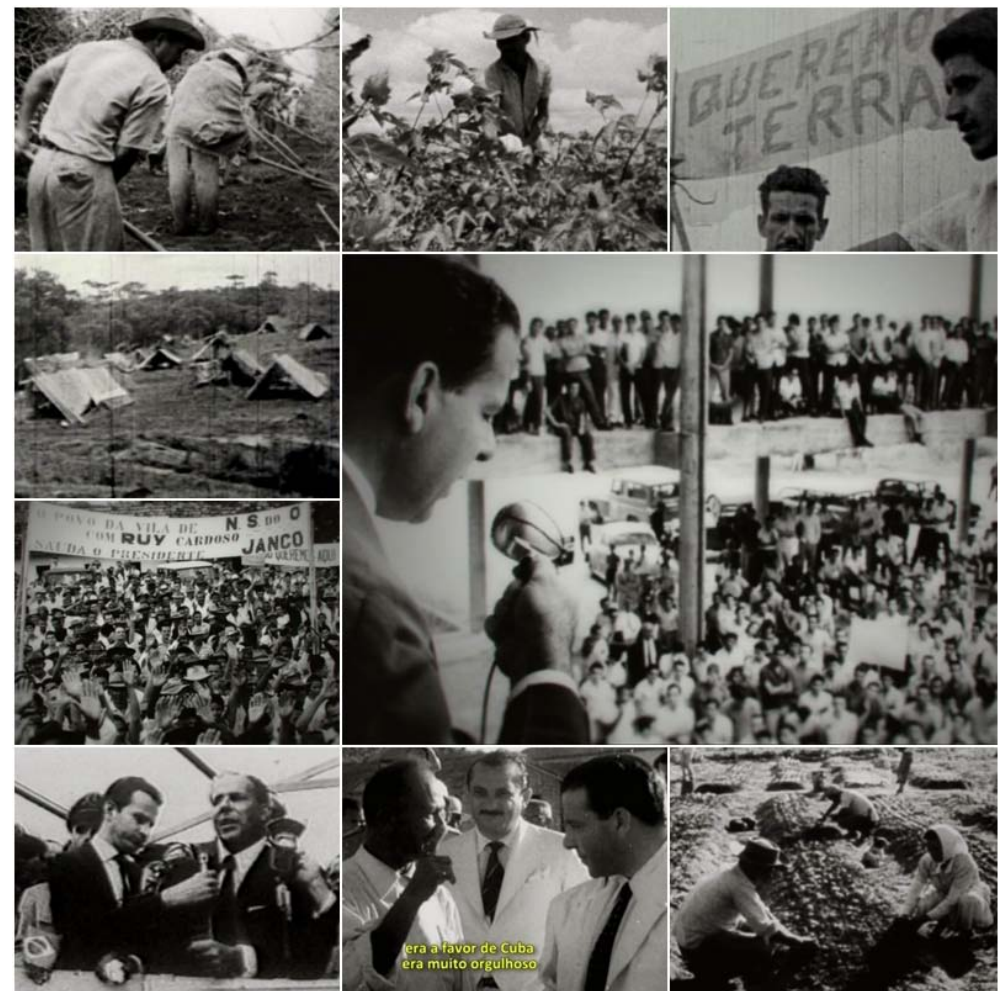

Fonte: Jango (1984), O dia que durou 21 anos (2012) e Militares da Democracia... (2014).

\footnotetext{
8 Os quatro elementos da cosmologia grega são terra, água, ar e fogo.

9 Pequenos produtores são comprovadamente aqueles que fornecem mais alimentos aos consumidores urbanos, diferentemente do agrobusiness, destinado ao comércio exterior.
} 


\subsection{0 mito do progresso}

Pauta principal do famoso discurso de Jango no Comício da Central do Brasil ${ }^{10}$, as Reformas de Base movimentam um simbolismo de poder ativado diretamente por estruturas do mundo histórico como economia, finanças e processo eleitoral. A fala do presidente constela imagens simbólicas de soberania, independência, autonomia, capacitação, igualdade e compartilhamento. Com isso, Jango movimenta o mito do progresso, trazendo ao plano das realidades imediatas um desejo de união entre o governo e o povo para o desenvolvimento socioeconômico com esforço e recompensa coletivos.

Figura 2: Comício da Central do Brasil, no Rio de Janeiro, em 1964.

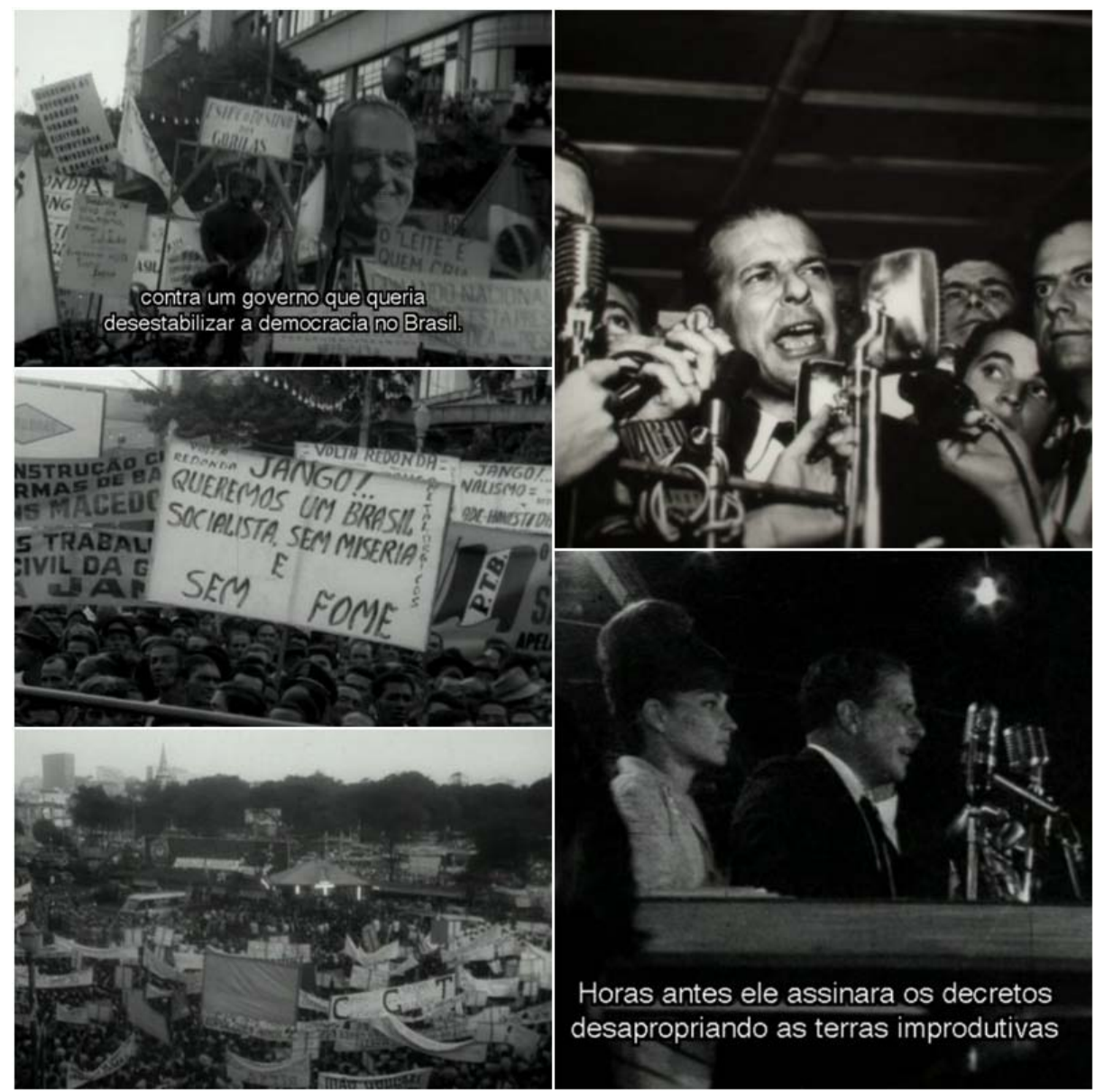

Fonte: Reproduções Jango (1984), O dia que durou 21 anos (2012) e Militares da Democracia (2014).

\footnotetext{
10 O comício realizado no dia 13 de março de 1964, no Rio de Janeiro, acompanhado por cerca de 200 mil pessoas, mobilizou
} "sindicatos e a esquerda pelo país inteiro", conforme o jornalista Flávio Tavares (2014, p. 174). 


\subsection{O deslocamento do simbolismo do centro}

João Goulart move a pauta sociopolítica da periferia governamental para o núcleo da Presidência da República, reposicionando o simbolismo do centro (ELIADE, 2002) ligado ao exercício de poder no Brasil. Neste simbolismo comum a sociedades arcaicas, e ainda presente na contemporaneidade, o centro não é geométrico nem geográfico, mas simbólico. Eliade explica que este centro "equivale à Criação do Mundo" (1992, p. 17), tamanha sua importância. Aqui, o "centro do mundo" é um local divino por excelência, onde o cosmo se centraliza e o sagrado se manifesta. Simbolicamente, o "centro do mundo" proporciona revelações, transcendência por imagens e atualização de sentidos, oferecendo entendimentos e valorizações de mundo. Muitos mitos, crenças e condutas estruturantes de realidades derivam do simbolismo do centro.

Como visto, simbolismos e mitos são recorrentes e reconfiguráveis. Apesar de contínuas degradações, surgem renovados, propondo novas explicações de mundo. No simbolismo do centro articulado pelo incipiente capitalismo brasileiro - e compartilhado pelas elites civis e militares nacionais -, o "centro do mundo" é um lócus fundador que movimenta emblemas do mundo financeiro e monetário, atualizando tanto um específico simbolismo de poder quanto imagens de concentração muito próprias. Com isso, potência e propriedade se atualizam como mitos contemporâneos, símbolos quase sagrados, modelos a serem seguidos cuja origem está em um sistema de produção e consumo em série do qual o Brasil do século XX não poderia escapar.

As elites brasileiras perdem a referência de seu próprio centro simbólico ${ }^{11}$ quando Jango desloca o simbolismo do centro do antigo governo federal, repleto de imagens e esquemas de individualismo e concentração, para o centro de seu próprio governo, situado nos campos mais à esquerda do imaginário sociopolítico. Neles, as imagens de coletividade e distribuição são muito pregnantes. Assim, no "centro do mundo" nacional proposto por Jango, a transcendência por imagens não se dá pelos símbolos corriqueiros do capitalismo excludente, que favorece poucos em detrimento de muitos, mas por imagens de riqueza coletiva, produção comunitária, convívio, equiparação e compartilhamento.

Nestes simbolismos do centro antagônicos, os anseios e os desejos de governistas e militares não dialogam. 0 acúmulo de bens e riquezas não concorda com sua distribuição, evidenciando algumas das principais raízes que levaram ao golpe. Há um conflito de ordem

\footnotetext{
11 Eliade explica que, em termos simbólicos, a ideia de "nosso mundo" liga-se à noção de "verdadeiro mundo", situando-se sempre no centro, "[...] pois é aí que há rotura de nível, comunicação entre as três zonas cósmicas [...]" (1992, p. 27), referindo-se ao Céu, à Terra e ao Mundo Inferior. 0 autor conclui que "nosso mundo" é o "centro do mundo", cosmo perfeito.
} 
simbólica entre os grupos que rondam o poder no Brasil no início dos anos 1960 que, em termos estruturais das realidades, se traduz em conspiração política pela tomada deste mesmo poder.

Conforme o ex-general do Exército Antonio Carlos Muricy, militares brasileiros queriam revidar duramente a "subversão levada pelo governo" (Jango, 1984, 01:02:2212) à época do comício da Central do Brasil. Muricy diz que oficiais impediriam a realização do comício de forma violenta, mas foram impedidos pelo comando militar - ciente que a revolta dentro do Exército contra "[...]um governo que estava querendo desestabilizar a democracia no Brasil." (Jango, 1984, 01:04:04) seria maior após a fala do presidente.

Aos poucos, as Forças Armadas articulavam mais nitidamente contra Jango, obtendo apoio do governo norte-americano. A influência externa, ideológica e financeira, aproximouse de segmentos políticos e civis opostos ao governo federal.

\section{Do mito do infiltrado ao mito do golpe de Estado positivo: a tomada de poder pelos militares}

Durante os anos 1960, a presença dos Estados Unidos em território nacional se torna mais visível. Jango (1984) e $O$ dia que durou 21 anos (2012) destacam a vigilância interna e externa, bem como a ingerência norte-americana no Brasil. Desde 1961, o então embaixador dos EUA em Brasília, Lincoln Gordon, acompanhava a trajetória pública e o perfil trabalhista de João Goulart. Figura central no processo político que levou ao golpe e à instauração da ditadura, Gordon é apontado pelo historiador Carlos Fico como um verdadeiro "[...] personagem da história política brasileira, tamanha a importância que a embaixada passou a ter naquele momento tão conturbado." (O dia que durou 21 anos, 2012, 06:46). Pesquisador com conhecimento da língua portuguesa, Gordon foi escolhido por Kennedy para ocupar o cargo quando estudava no Rio de Janeiro. Conforme o historiador James Green, o embaixador pretendia evitar um governo de esquerda no Brasil, bloqueando as ações de Jango.

Com facilidade, o embaixador passa a integrar os núcleos de poder em Brasília, marcando presença pessoal e institucional norte-americana junto à Presidência da República, e repassando informações essenciais a Kennedy ${ }^{13}$. Na capital federal, Gordon

\footnotetext{
12 A numeração 01:02:22 refere-se à minutagem em que a informação é apresentada no filme em questão. A partir de agora, grafaremos neste modelo as referências a todos os dados fílmicos citados.

13 Por telegramas, cartas, ligações telefônicas e em reuniões presenciais, a cujos registros Flávio e Camilo Tavares tiveram acesso, nos Estados Unidos, durante a produção de $O$ dia que durou 21 anos.
} 
executava as estratégias definidas junto a Washington com apoio do ex-adido militar dos Estados Unidos no Brasil, general Vernon Walters. Ambos tinham contato próximo com a elite militar brasileira, incluindo o general Castelo Branco, atuando para ampliar o clima interno de oposição a Jango.

Gordon convenceu o Departamento de Estado norte-americano de que João Goulart iria implantar no Brasil uma república sindicalista e perderia o controle para comunistas $(O$ dia que durou 21 anos, 2012, 08:22). Para o historiador Peter Kornbluh, “[...] os Estados Unidos queriam apresentar Goulart como um presidente de extrema esquerda [...]", então a distribuição de terras "[...] era mais um pretexto para apoiar este argumento." ( $O$ dia que durou 21 anos, 2012, 09:14). Fico conclui que os EUA não admitiriam em hipótese alguma “[...] outra Cuba, outro governo na América Latina de viés comunista ou socialista [...] mesmo que tivessem que perpetrar quaisquer violências" (O dia que durou 21 anos, 2012, 16:23).

Figura 3 - Áudio de $O$ dia que durou 21 anos registra Kennedy e Gordon articulando contra Jango.

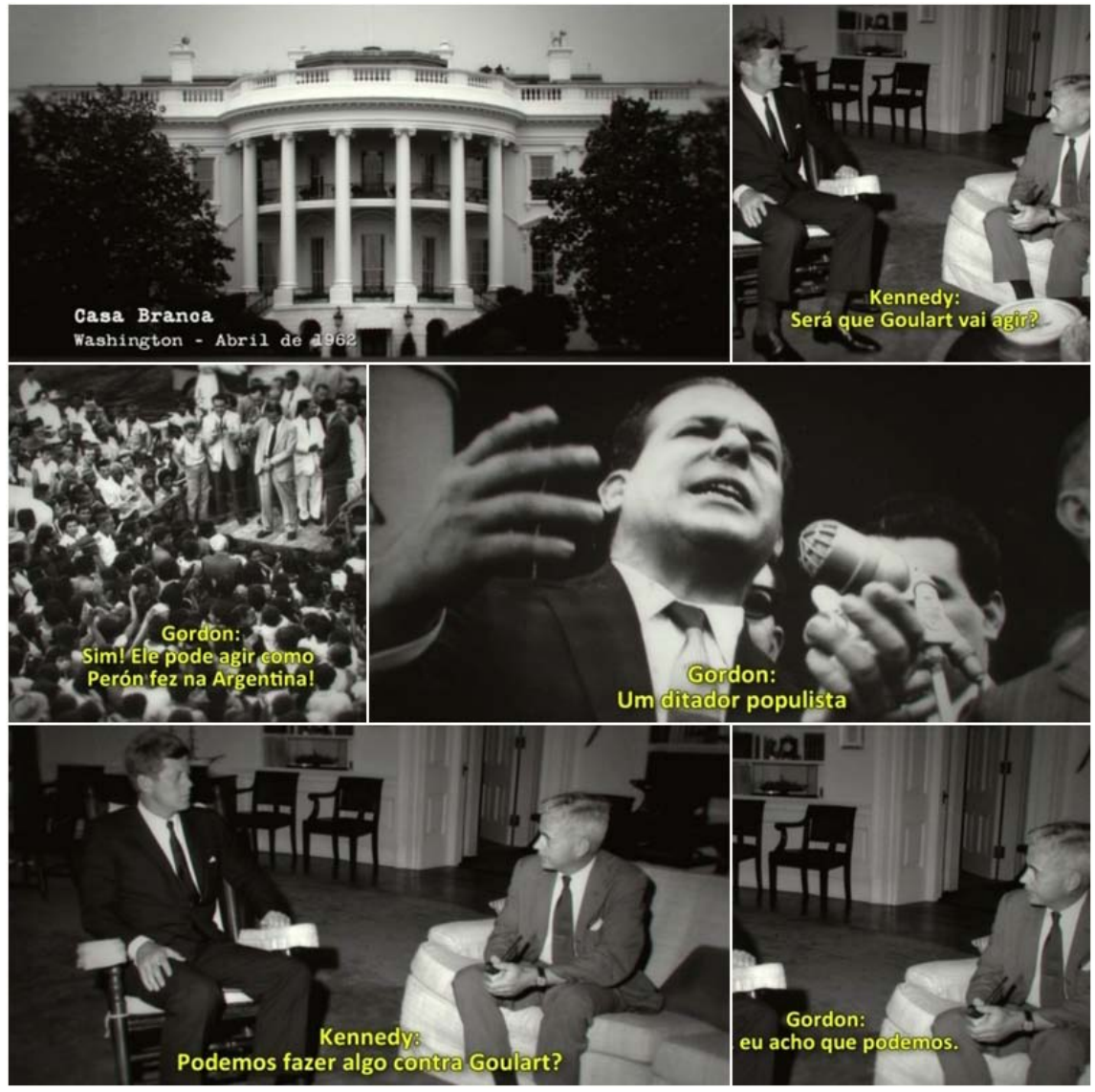

Fonte: Reproduções de $O$ dia que durou 21 anos (2012). 
Os Estados Unidos reforçaram a oposição a Jango em várias frentes. Com a Aliança para o Progresso, investiram US\$ 2 milhões em educação, agricultura e infraestrutura. Financiaram o Instituto de Pesquisas e Estudos Sociais (Ipes), cujos filmes de propaganda política exibidos em cinemas, empresas e praças do interior anunciavam "as crises, o descalabro administrativo e a desordem" (O dia que durou 21 anos, 2012, 17:20). Já o Instituto Brasileiro de Ação Democrática (Ibad), ligado aos EUA, fazia lobby junto à imprensa, plantava notícias falsas e ampliava a sensação de ameaça comunista. Também houve pagamento de propina a políticos ${ }^{14}$.

Para desestabilizar Jango, Kennedy se aproximou dos governadores do Rio de Janeiro, Carlos Lacerda, e de São Paulo, Ademar Pereira de Barros. Paralelamente, Vernon Walters conspirava com militares, observando entre eles quais seriam os mais fiéis ao apoio norte-americano. 0 general Humberto de Alencar Castelo Branco saiu na frente.

Figura 4 - Gordon frequentava a cúpula do governo brasileiro (no alto) e Kennedy mantinha contato com os governadores de São Paulo, Ademar de Barros (centro, à direita), e do Rio de Janeiro, Carlos Lacerda (abaixo, à direita).

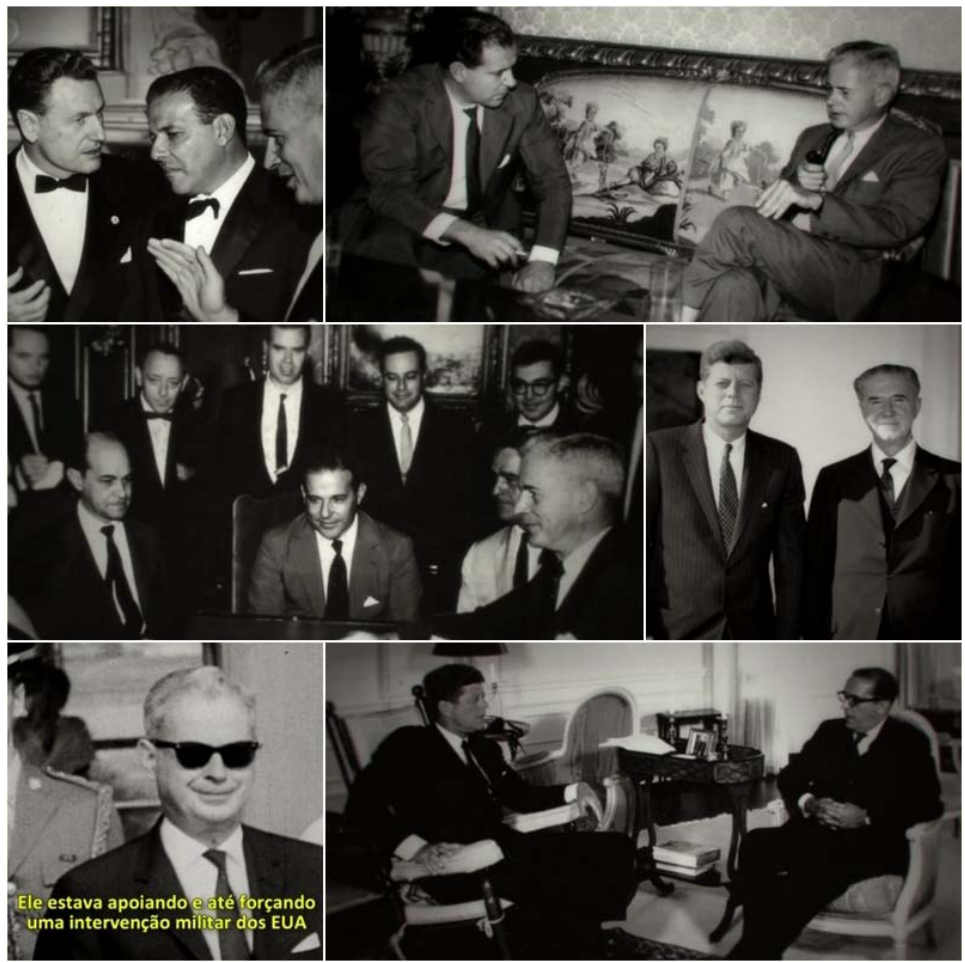

Fonte: Reproduções de Jango (1984).

\footnotetext{
14 As denúncias de financiamento ilegal de candidatos a cargos de deputado e de governador resultaram em uma Comissão Parlamentar de Inquérito (CPI) para investigar o Ibad em maio de 1962. Posteriormente, a capa do jornal Última Hora de 13 de novembro de 1971 informou que o Ibad havia repassado verbas a 250 deputados federais, oito governadores e 600 deputados estaduais para fazerem frente a Jango nas eleições de 1962.
} 
Para ampliar o sentimento anticomunista na sociedade, Gordon ajuda a organizar a Marcha da Família com Deus pela Liberdade (O dia que durou 21 anos, 2012, 23:40), movimento que teve início em São Paulo, em março de 1964, em resposta ao comício de Jango na Central do Brasil, e que reuniu um milhão de pessoas no Rio de Janeiro em abril do mesmo ano. Na tentativa de conter a disseminação continental do comunismo a partir de Cuba, a presença norte-americana se espalhou entre Brasil e outros países sul-americanos. Assim, os Estados Unidos perpetraram uma dominação hemisférica de natureza econômica e ideológica antes que seus opositores fizessem o mesmo.

Com acesso a Executivo, Legislativo, Forças Armadas e sociedade, os EUA promoveram pressão financeira e econômica, propaganda ideológica, assédio cultural, golpes midiáticos e financiamento de políticos, acionando o simbolismo de poder. Nele, constelam sensos e imagens beligerantes de imperialismo, espionagem, intromissão, ingerência e dominação. Na realidade existencial da cultura e da vida dos brasileiros, este simbolismo direciona ações de inteligência, contrainteligência e tráfico de influência, sempre fundamentadas em desejos reais de obtenção de mercados e controle geopolítico.

\subsection{O mito do infiltrado}

A abordagem norte-americana ao Brasil remete ao mito do infiltrado, elemento recorrente no imaginário da guerra que desperta práticas concretas entre sociedades em conflito. $\mathrm{O}$ infiltrado é o sujeito de fora e que se passa por alguém de dentro, ou ainda o estrangeiro ou forasteiro dissimulador de suas reais intenções. Ao lançar mão do infiltrado, um dos lados da discórdia busca dominar o outro a partir de dentro, com discrição, reunindo informações sobre o inimigo, cooptando colaboradores em solo adversário, espalhando rumores, instaurando desavenças, preparando um clima de pessimismo generalizado e de oposição às lideranças. Em $A$ arte da guerra, tratado militar escrito por volta de IV a.C., Sun Tzu ${ }^{15}$ explica:

Procura obter todas as informações sobre o inimigo. Informa-te exatamente de todas as suas relações, suas ligações e interesses recíprocos. Não poupes grandes somas de dinheiro. Não lamentes o dinheiro empregado seja no campo inimigo, para conseguir traidores ou obter conhecimentos exatos, seja para o pagamento dos teus soldados:

\footnotetext{
${ }^{15} \mathrm{O}$ general, estrategista e filósofo chinês Sun Tzu teria servido o rei Hu Lu, da província de Wu, no período da história chinesa conhecido como Primavera e Outono (de 722 a 481 a.C). A época em que viveu e sua própria existência ainda hoje geram debate entre historiadores.
} 
quanto mais gastares, mais ganharás. [...] Mantém espiões por toda a parte. Informa-te de tudo, nada negligencies do que descobrires. Mas, tendo descoberto algo, sê extremamente discreto. [...] 0 grande segredo para vencer sempre consiste na arte de semear a divisão: nas cidades e nas aldeias, no exterior, entre inferiores e superiores, de morte, e de vida (SUN, 2006, p. 75-76).

Diz Sun que a infiltração ideal reverte-se em pessoas inteiramente devotadas muito rapidamente, sendo o infiltrado quem sugere aos mestres da guerra o caminho da conquista. De fato, conforme os documentários estudados, após muitas ações estrangeiras em solo nacional a sociedade brasileira gradativamente deixa de apoiar Jango e as reformas de base. Por fim, Sun conclui que a infiltração resulta em cerco e dominação "sem dar o assalto, sem desferir nenhum golpe ${ }^{16}$, sem desembainhar a espada." (2006, p. 77). 0 infiltrado prepara o terreno para que a dominação se dê preferencialmente sem conflitos armados, tendo os líderes locais ao seu lado. Conforme o corpus de pesquisa, este foi o resultado da infiltração norte-americana no Brasil: uma dominação externa indireta, com apoio de setores internos, sem confronto deflagrado, sem resistência por parte do governo de João Goulart. 0 inimigo infiltrado não desembainhou a espada para concluir seu plano de dominação. Porém, a população brasileira viria a sofrer opressão, censura e violência por longo período após o golpe de 1964.

0 mito do infiltrado coloca em movimento o simbolismo da intimidade ${ }^{17}$, marcado pelo arquétipo de interioridade e por imagens que dele decorrem - claustro, casa, palácio, sede, caserna, entre outras. Essa carga simbólica deriva da documentação audiovisual relativa ao livre trânsito de Lincoln Gordon e de Vernon Walters entre o Palácio da República, as sedes federais e os quartéis generais brasileiros (Figuras 4 a 6) antes e depois da queda de Jango. Os dois norte-americanos infiltrados colocaram em prática uma agenda externa não totalmente clara até então, estimulando sensos de mistérios e segredos próprios do simbolismo da intimidade.

\footnotetext{
${ }^{16} 0$ termo golpe aqui guarda um sentido de luta, agressão física, e não de golpe de Estado.

17 Regido por imagens arquetípicas de interioridade, o simbolismo da intimidade circula imagens de sepulcro, claustro, morada, casa, templo, palácio, cabana, cave, gruta. Complementarmente, ativa imagens de centro, círculo e lugar sagrado protetor, além de imagens de ventre e intimidade materna (DURAND, 2012, p. 236-268). Neste documentário, estas imagens se traduzem nas sedes republicanas de poder.
} 
Figura 5 - Após a Marcha da Família com Deus pela Liberdade (no alto, ao centro e abaixo), Gordon solicita aos EUA o envio de uma frota naval de guerra em direção ao litoral brasileiro. A ação, nunca levada a cabo, ficou conhecida como Operação Brother Sam.

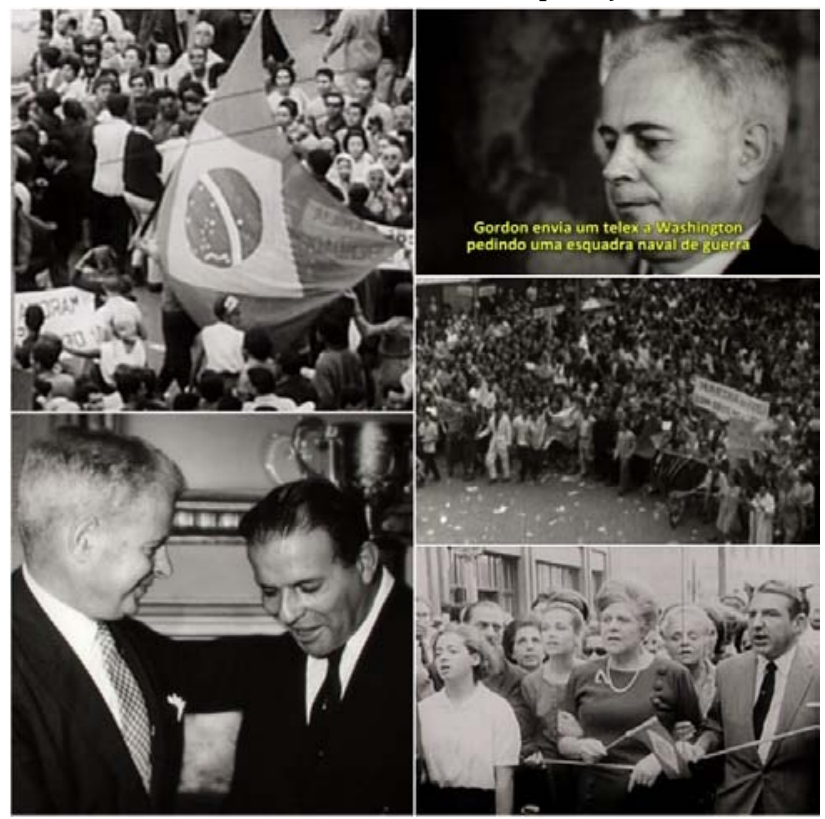

Fonte: Reproduções de Jango (1984) e O dia que durou 21 anos (2012).

Os pensamentos militares de Sun não são narrativas míticas, mas ecoam condutas antropológicas há muito praticadas, cujos processos e resultados socialmente assimilados e simbolicamente mitificados passaram a integrar a cultura humana e o imaginário da guerra.

\subsection{O golpe civil-militar e a Operação Brother Sam}

Após a Marcha da Família, ápice da oposição a Jango, Gordon pede a vinda de uma frota naval norte-americana à costa brasileira. Ao deixar de lado qualquer discrição sobre a ingerência externa no país, sinaliza tanto "uma ameaça a Goulart e seus aliados" quanto um apoio aos "militares conspiradores", segundo Kornbluh (O dia que durou 21 anos, 2012, $35: 33)$.

Um porta-aviões e seis navios chegariam a Santos (SP) no dia 10 de abril de 1964, garantindo apoio bélico ao golpe civil-militar que já estava em andamento sob comando de lideranças paulistas e mineiras desde a madrugada do dia $1^{\mathrm{o}}$ de abril, quando tropas do general Mourão Filho seguiram de Minas Gerais para o Rio de Janeiro. Na chegada à capital fluminense não houve resistência. Jango não combateu Mourão. A fraqueza de seu esquema militar seria um dos motivos, conforme Plínio de Arruda Sampaio (O dia que durou 21 anos, 2012, 42:00), deputado federal entre 1962 e 1964. 
Jango deixa o Rio, vai a Brasília, segue para Porto Alegre e, posteriormente, chega a Montevidéu com integrantes do governo federal. Sem resistência presidencial, a frota norteamericana que se dirigia a Santos retorna a seu posto, desarticulando a Operação Brother Sam. Em sua comunicação direta com Washington, Gordon informa que “[...] a eliminação de Goulart representa uma grande vitória ao mundo livre [...]”, afirmando também que o povo comemora nas ruas e que "[...] comunistas e elementos de esquerda estão sendo presos sob a Lei de Segurança Nacional." (O dia que durou 21 anos, 2012, 44:50).

Figura 6 - A cúpula militar brasileira, representada por Costa e Silva (acima, à esquerda) e por Castelo Branco (acima, ao centro e abaixo) mantinha relações com Lincoln Gordon (ao centro) e com Vernon Walters (abaixo, à direita).

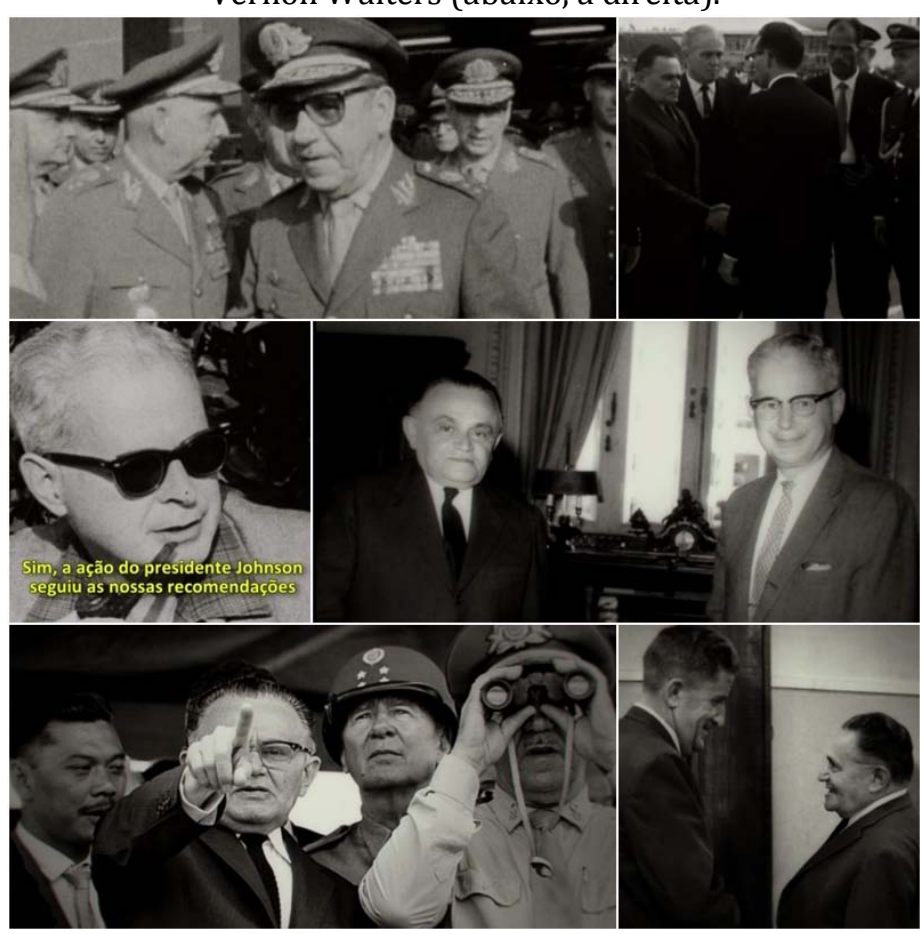

Fonte: Reproduções de Jango (1984) e $O$ dia que durou 21 anos (2012).

A Presidência da República foi declarada vaga pelo então presidente do Congresso Nacional, Auro de Moura Andrade, enquanto Jango ainda encontrava-se no Brasil. Com isso, uma junta militar composta pelo tenente-brigadeiro Francisco de Assis Correia de Melo, pelo general Artur da Costa e Silva e pelo almirante Augusto Rademaker declara Ranieri Mazzili presidente interino do Brasil. Em seguida, os militares instauram o Ato Institucional no 1 (AI-1) no dia 9 de abril de 1964 (BRASIL, 1964), desestabilizando o cenário político nacional. Com o AI-1 a junta militar convoca eleições indiretas e suspende os direitos políticos de 300 pessoas. 
No dia 11 de abril de 1964, o general Castelo Branco é eleito presidente indiretamente. Os Estados Unidos reconhecem o novo governo brasileiro de imediato. $\mathrm{Na}$ posse, Castelo Branco disse que não compactuaria com uma "direita reacionária" para combater "os malefícios da extrema esquerda", ignorando as medidas do AI-1. Na verdade, seu governo deu início a um período de intolerância civil que assumiria proporções dramáticas nos anos seguintes. Ainda em meados de abril, um telegrama de Gordon para Washington informa sobre a "Operação Limpeza", que teria resultado em três mil prisões sob acusação de atividade subversiva.

Figura 7 - Logo após o golpe, o Exército e as polícias passaram a reprimir mobilizações sociais e atividades políticas.

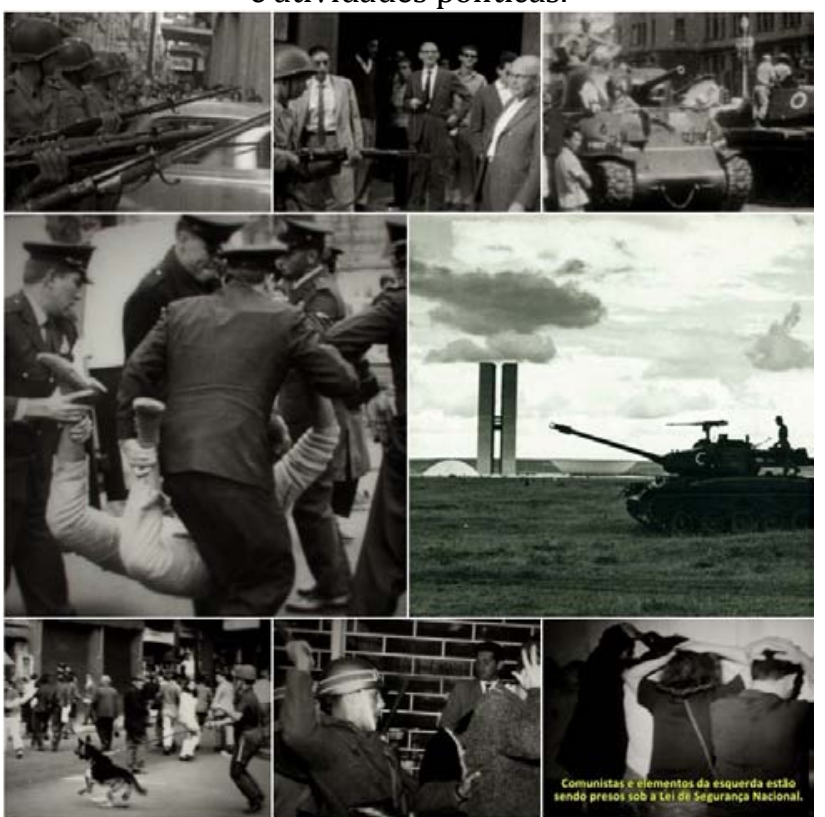

Fonte: Reproduções de Jango (1984) e O dia que durou 21 anos (2012).

\subsection{O mito do golpe de Estado positivo}

Apesar do discurso de posse supostamente democrático, Castelo Branco mostrou o perfil reacionário do regime militar rapidamente, logo após a derrubada de Jango. Portanto, o golpe civil-militar brasileiro movimenta o mito do golpe de Estado positivo, porém às avessas. Nele, a imagem arquetípica de poder, que emite imagens simbólicas de potência, força e dominação, bem como sentidos de estratégia, ação e eficácia, estabelece narrativas sobre a disputa e o sequestro deste poder no mundo histórico. No golpe de Estado positivo, um governo passa a ser questionado por um grupo, que toma o poder alegando a necessidade de afastar governantes autoritários ou corruptos. Dado o golpe, o grupo tende a 
devolver o governo democrático ao povo. Um conhecido golpe de Estado positivo é a Revolução dos Cravos, em Portugal, pela qual uma revolta de oficiais do Exército derrubou o ditador António de Oliveira Salazar, em abril de 1974, levando o país à democracia.

No Brasil, no entanto, o golpe de Estado não apresentou seu lado positivo. Se em discurso Castelo Branco disse que tomaria o poder evitando uma ação da "direita reacionária", posteriormente o general imprimiu repressão e evitou devolver o poder ao povo. Repassou-o a Artur da Costa e Silva em 15 de março de 1967, após nova eleição indireta. Portanto, o golpe no Brasil se deu não para libertar a nação de um governo supostamente autoritário ou corrupto, reconduzindo-a à democracia, mas sim para controlar rigidamente o país e sua população segundo uma agenda político-econômica desvinculada dos benefícios sociais de um Estado livre. Em 1964, o objetivo não era entregar o processo político à população, mas cerceá-la deste privilégio.

\section{Pelo imaginário da ditadura militar}

A revelação do imaginário antropológico que movimenta seis filmes sobre o regime militar brasileiro apresentou uma série de desafios à pesquisa. Entre eles, está a própria observação e leitura dos conteúdos simbólicos e polissêmicos que emanam da documentação audiovisual. Elementos com origem no trajeto antropológico durandiano, que conecta as pulsões do homem às coerções do meio no qual ele vive, as imagens permitem leituras simbólicas plurais, que variam conforme a própria experiência do sujeito-leitor, bem como de seu contexto histórico-social.

Neste artigo, trouxemos à luz imagens arquetípicas e simbólicas mobilizadoras do simbolismo da terra, do mito do progresso, do simbolismo do centro, do mito do infiltrado e do mito do golpe de Estado positivo - elementos que se movimentam entre a posse de Jango e o golpe civil-militar que o derrubou.

Em um próximo artigo, daremos atenção ao desenvolvimento do regime ditatorial, à intensificação da repressão, às movimentações da luta armada e de militares opostos ao autoritarismo, sem esquecer da redemocratização do país. Com isso, colocaremos em evidência conteúdos imaginários como a imagem arquetípica do herói, as imagens simbólicas do ovo e da serpente, além dos simbolismos catamórfico, ascensional e espetacular. Ao observar o trânsito de outros componentes imaginários no processo comunicacional instaurado por documentários, poderemos revelar os sentidos simbólicos e míticos atrelados a esse momento da história recente do Brasil. 


\section{Referências}

BRASIL. Ato Institucional no 1 . Brasília, de 9 de abril de 1964. Diário Oficial [da] União, Rio de Janeiro, 9 abr. 1964. p. 3193, col. 1. Republicado em 11 abr. 1964. p. 3257, col. 1. Disponível em: <http://www.planalto.gov.br/ccivil_03/AIT/ait-01-64.htm>. Acesso em: 1 ago. 2015.

BACHELARD, Gaston. A terra e os devaneios da vontade: ensaio sobre a imaginação das forças. São Paulo: Martins Fontes, 2001.

BACHELARD, Gaston. 0 ar e os sonhos. São Paulo: Martins Fontes, 1990.

CIDADÃo Boilesen. Roteiro e direção: Chaim Litewski. Produção: Pedro Asbeg e Chaim Litewski. Estúdio: Palmares Produções Cinematográficas. 2009. 1 DVD.

DOSSIÊ Jango. Roteiro e direção: Paulo Henrique Fontenelle. Produção: Tereza Alvarez. Estúdio: Canal Brasil. 2013. 1 DVD.

DURAND, Gilbert. A imaginação simbólica. Lisboa: Edições 70, 2000.

DURAND, Gilbert. As estruturas antropológicas do imaginário: introdução à arquetipologia geral. São Paulo: Martins Fontes, 2012.

DURAND, Gilbert. Campos do imaginário. Lisboa: Instituto Piaget, 1996.

DURAND, Gilbert. 0 imaginário: ensaio acerca das ciências e da filosofia da imagem. Rio de Janeiro: DIFEL, 1998.

ELIADE, Mircea. Imagens e símbolos: ensaio sobre o simbolismo mágico-religioso. São Paulo: Martins Fontes, 2002.

ELIADE, Mircea. 0 sagrado e o profano. São Paulo: Martins Fontes, 1992.

FANTINEL, Danilo. 0 ovo da serpente, o mito do golpe de Estado positivo e a queda: do documentário histórico ao imaginário antropológico da ditadura militar brasileira. 2015. Dissertação (Mestrado em Comunicação e Informação) - Universidade Federal do Rio Grande do Sul, RS. Disponível em: <http://www.lume.ufrgs.br/handle/10183/132256>. Acesso em: 13 jan. 2016.

FLUSSER, Vilém. A filosofia da caixa preta: ensaios para uma futura filosofia da fotografia. São Paulo: Annablume, 2011.

HISTÓRIA e Audiovisual: circularidades e formas de comunicação. Filmografia sobre o regime militar. São Paulo, [201-].

JANGO. Roteiro e direção: Silvio Tendler. Produção: Caliban Produções Cinematográficas. 1984. 1 DVD.

JUNG, Carl Gustav. 0 eu e o inconsciente. Petrópolis: Vozes, 1978. 
JUNG, Carl Gustav. Os arquétipos e o inconsciente coletivo. Petrópolis: Vozes, 2002.

MARIGHELLA. Roteiro e direção: Isa Grispum Ferraz. Produção: Pablo Torrecillas, Rodrigo Castellar e Isa Grinspum Ferraz. Estúdio: Tc Filmes. 2011. 1 DVD.

MILITARES da Democracia: os militares que disseram não. Roteiro e direção: Silvio Tendler. Produção: Projeto Marcas da Memória, da Comissão de Anistia. 2014.

O DIA que durou 21 anos. Roteiro e direção: Camilo Tavares. Produção: Flávio Tavares, Camilo Tavares, Karla Ladeia. Estúdio: Pequi Filmes. 2012. 1 DVD.

RAMOS, Fernão Pessoa. Mas afinal... o que é documentário? São Paulo: Editora Senac, 2013.

SUN, Tzu. A arte da guerra. Porto Alegre: L\&PM, 2006.

TAVARES, Flávio. 1964, o golpe. Porto Alegre: L\&PM, 2014.

\title{
From historical documentary to the anthropological imaginary of the Brazilian dictatorship: a symbolic view of the 1964 military coup d'État
}

\begin{abstract}
This paper presents a symbolic view on the military coup d'État that resulted in the Brazilian dictatorship, which took place in April $1^{\text {st }}, 1964$. Inspired by the Imaginary Studies, this paper aims to reveal the anthropological imaginary related to six documentary films on that subject. Taking textual, visual and audio documentation collected from the movies, this research presents a myth criticism of the films in order to offer evidences of archetypal images, symbolisms and myths that are hidden under the documentaries surfaces.
\end{abstract}

\section{Keywords}

Military regime. Dictatorship. Brazil. Imaginary. Documentary.

Recebido em: 01/02/2017

Aceito em: 12/06/2017 